Jurnal IImiah Teknik Informatika, Elektronika dan Kontrol (Scientific Journal of Informatics, Electronics and Control Engineering)

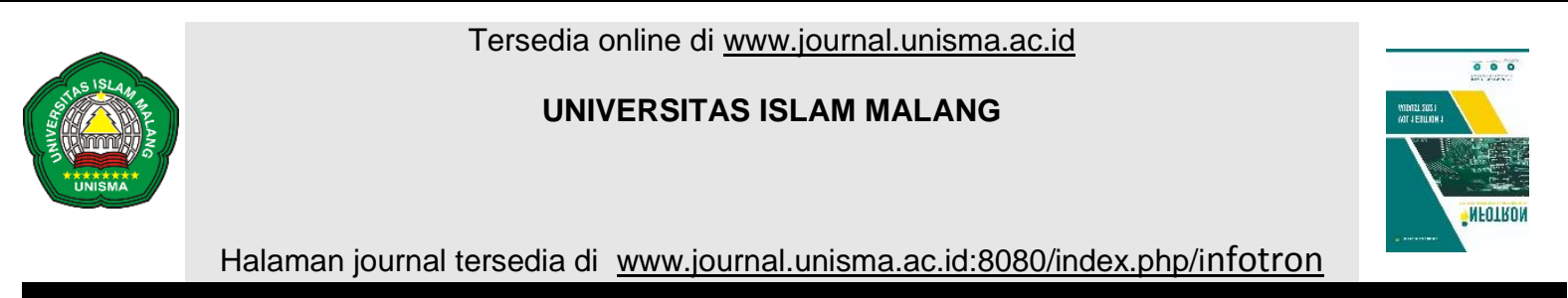

\title{
Analisis Perawatan Dan Penanganan Gangguan Pada Trafo Distribusi 20 KV Di PT. PLN (Persero) Lamongan Rayon Brondong Berbasis Tinjauan Power Quality
}

\author{
Zainal Abidin, Ahmad Sakbi Mubarok \\ Prodi Teknik Elektro Universitas Islam Lamongan \\ e-mail :, zaenalabidinunisla@gmail.com, sakbimubarok@gmail.com
}

\begin{tabular}{l} 
INFORMASI \\
ARTIKEL \\
\hline \\
Sejarah artikel: \\
Received 6 Mei 2021 \\
Accepted 3 Juni 2021 \\
\hline
\end{tabular}

\section{Kata kunci:}

Perawatan transformator, transformator distribusi, keandalan daya

\begin{abstract}
A B S T R A K
Metode perawatan serta penanganan gangguan pada trafo distribusi $20 \mathrm{kv}$ di PT. PLN (persero) rayon Brondong digunakan metode power quality atau kualitas daya yang mana dengan menggunakan alat ukur mega ohm meter (megger meter) dan untuk menjaga keandalan daya yaitu dengan menggunakan aplikasi ETAP 12.6.0 untuk mengukur frekwensi tegangan, kesetabilan tegangan, harmonisa tegangan, dan drop tegangan. hasil analisa dalam perawatan trafo distribusi $20 \mathrm{Kv}$ di PT. PLN (persero) Rayon Brondong dengan pengukuran yang telah dianalisa tahanan isolasi dengan Mega Ohm Meter (megger tester) 500/1000 $\mathrm{V}$ hanya ada satu trafo yang kumparanya bocor yaitu pada trafo nomor 7 yang ada di tabel dalam 10 sample yang diambil. Dan mengukur keandalan daya dengan menentukan frekwensi sistem dengan menggunakan program ETAP 12.6.0, data kesetabilan tegangan hanya pada feeder Pambon dan Solokuro yang nilai Harmonisnya dan drop tegangan pada PLN Rayon Brondong masih memenuhi standart PLN kecuali feeder pambon dan solokuro. Pada penanganan gangguan dan kerusakan $20 \mathrm{Kv}$ di PT. PLN (persero) Rayon Brondong telah memenuhi kualitas daya (power quality) karena pada penanganan gangguan telah memenuhi Standar Operasional Prosedur PLN. Dan saat kerusakan pada trafo, PT. PLN (persero) Rayon Brondong langsung mengganti dengan trafo yang baru atau diganti dengan trafo mobil (semi permanen) yang di datangkan langsung dari PT. PLN (Persero) distribusi jawa timur area Bojonegoro.
\end{abstract} (๑) 2021 INFOTRON: Jurnal IImiah Teknik Informatika, Elektronika dan Kontrol (Scientific Journal of Informatics, Electronics and Control Engineering).

\section{Pendahuluan [Kepala Bagian]}

PT.PLN (Persero) merupakan BUMN yang menyediakan tenaga listrik bagi seluruh lapisan masyarakat yang semakin hari semakin dibutuhkan keberadaanya.

Perawatan gardu distribusi tiang portal bertujuan untuk mencegah terjadinya kerusakan peralatan secara tiba-tiba, untuk mempertahankan unjuk kerja peralatan yang optimum sesuai umur teknisnya Timbulnya gangguan pada transformator distribusi mengakibatkan kerusakan pada trafo dan terputusnya penyaluran tenaga listrik ke pelanggan. Rumusan masalah dari penelitian adalah: a) Bagaimana cara perawatan pada trafo distribUntuk mengetahui perawatan pada Trafo Distribusi $20 \mathrm{KV}$ di PT. PLN (persero) Unit Brondong apakah sudah memenuhi kualitas daya, b) Untuk mengetahui penyebab gangguan dan kerusakan serta penanganan Pada trafo distribusi 20KV. 


\section{State of the Art}

Dalam metode perawatan serta penanganan gangguan pada trafo distribusi $20 \mathrm{kv}$ di PT. PLN (persero) rayon Brondong penulis menggunakan metode power quality atau kualitas daya yang mana dengan menggunakan alat ukur mega ohm meter (megger meter) dan untuk menjaga keandalan daya yaitu dengan menggunakan aplikasi ETAP 12.6.0 untuk mengukur frekuensi tegangan, kesetabilan tegangan, harmonisa tegangan, dan drop tegangan.

\section{Method}

Metode dikaitkan dengan validitas dan reliabilitas hasil penelitian untuk mengukur frekuensi tegangan, kesetabilan tegangan, harmonisa tegangan, dan drop tegangan.

\section{Hasil and Pembahasan}

\section{Perawatan Transformator}

Perawatan dilakukan dengan dua tahapan yaitu :

\section{a) Perawatan Jangka Pendek}

Didalam pemeliharaan jangka pendek pada transformator dilakukan hanya bersifat pengontrolan dan perbaikan yang kecil saja, dan waktu perbaikan tidak mengganggu kerja transformator. $r$.

\section{b) Perawatan Jangka Panjang}

Untuk pemeliharaan jangka panjang ini dilaksanakan dengan jadwal yang ditentukan dan transformator dalam keadaan tidak beroperasi, yang bebas dari sumber maupun beban. Pemeliharaan yang dilakukan antara lain :

1. Pembersihan Transformator dan Alat Perlengkapan

2. Pengujian Minyak Transformator.

3. Pengecekan Tahanan Isolasi.

4. Pengecekan Nilai Tahanan Pentanahan

\section{Pengukuran trafo dengan Mega Ohm Meter (magger)}

pengukuran trafo distribusi dengan menggunakan Mega Ohm Meter (megger) pada pengukuran tahanan isolasi trafo (megger 500 / $1000 \mathrm{~V}$ ) penulis mengambil sampel / contoh 10 trafo distribusi yang ada di tabel berikut:

Pada hasil pengukuran trafo distribusi hanya mengambil 10 sample trafo denganpengukuran nilai tahanan yaitu:

1. Merk: Trafindo

- Daya: 200 Kva

- $\quad$ Titik Trafo: MF085

- Tegangan primer : $20 \mathrm{Kv}$

- Tegangan sekunder: 392/213

dengan pengukuran tahanan isolasi:

- Pimer-Sekunder $=25 \Omega \mathrm{ohm}$

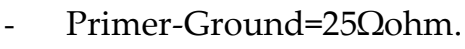




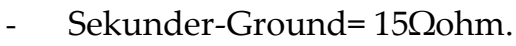

2. - Merk: Sintra

- Daya: 200 Kva.

- $\quad$ Titik Trafo: MF127.

- $\quad$ Tegangan primer : 21-18 Kv.]

- Tegangan sekunder: 230-400

dengan pengukuran tahanan isolasi:

- $\quad$ Pimer-Sekunder $=25 \Omega \mathrm{ohm}$.

- $\quad$ Primer-Ground $=25 \Omega \mathrm{ohm}$.

- Sekunder-Ground $=15 \Omega$ ohm

3. - Merk: B\&D

- Daya:100.

- $\quad$ Titik Trafo: MF146.

- Tegangan primer: 20Kv

- Tegangan sekunder: 400/231

dengan pengukuran tahanan isolasi:

- $\quad$ Pimer-Sekunder $=15 \Omega$ ohm .

- $\quad$ Primer-Ground $=15 \Omega \mathrm{ohm}$.

- $\quad$ Sekunder-Ground $=13 \Omega$ ohm

4. - Merk: B\&D (2012)

- Daya: 250Kva.

- Titik Trafo: MF206.

- Tegangan primer: $20 \mathrm{Kv}$.

- Tegangan sekunder: 400/231

dengan pengukuran tahanan isolasi:

- Pimer-Sekunder $=20 \Omega$ ohm .

- $\quad$ Primer-Ground $=10 \Omega \mathrm{ohm}$.

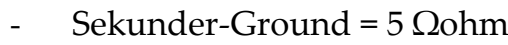

5. - Merk: BAMBANG DJAJA

- Daya: 200kva.

- $\quad$ Titik Trafo: MF195.

- Tegangan primer: $20 \mathrm{Kv}$.

- Tegangan sekunder: 400/231

dengan pengukuran tahanan isolasi:

- $\quad$ Pimer-Sekunder $=20 \Omega$ ohm . 
Abidin.Z, dkk. et. al./INFOTRON 1 (1) 2021 hal. 11-23

- $\quad$ Primer-Ground $=10 \Omega \mathrm{ohm}$.

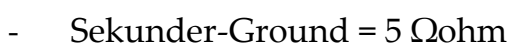

6. - Merk: Sintra (2010)

- Daya: 100.

- Titik Trafo: MF211 .

- Tegangan primer:20Kv.

- Tegangan sekunder:400/231.

dengan pengukuran tahanan isolasi:

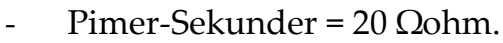

- $\quad$ Primer-Ground $=20 \Omega \mathrm{ohm}$.

- $\quad$ Sekunder-Ground $=10 \Omega$ $\Omega$ mm

7. - Merk: Sintra

- Daya: 100.

- $\quad$ Titik Trafo: MF070.

- Tegangan primer: 20Kv.

- Tegangan sekunder: 408/231

dengan pengukuran tahanan isolasi:

- Pimer-Sekunder $=10 \Omega$ Sohm .

- $\quad$ Primer-Ground $=15 \Omega \mathrm{ohm}$.

- $\quad$ Sekunder-Ground $=15 \Omega$ $\Omega$ m

8. - Merk: Trafindo

- Daya: 200Kva.

- $\quad$ Titik Trafo: MF089.

- Tegangan primer: $20 \mathrm{Kv}$.

- Tegangan sekunder:400/231

dengan pengukuran tahanan isolasi:

- $\quad$ Pimer-Sekunder $=20 \Omega$ ohm .

- $\quad$ Primer-Ground $=10 \Omega \mathrm{ohm}$.

- $\quad$ Sekunder-Ground $=10 \Omega$ ohm

9. - Merk: BAMBANG DJAJA

- Daya: 250Kva.

- $\quad$ Titik Trafo: MF083.

- Tegangan primer: $20 \mathrm{Kv}$.

- Tegangan sekunder: 400/231 
dengan pengukuran tahanan isolasi:

- $\quad$ Pimer-Sekunder $=25 \Omega$ ภohm.

- $\quad$ Primer-Ground $=15 \Omega \mathrm{ohm}$.

- $\quad$ Sekunder-Ground = $15 \Omega$ ohm

10. - Merk: B\&D.

- Daya: 200Kva.

- $\quad$ Titik Trafo: MF221.

- Tegangan primer: 20Kv.

- Tegangan sekunder: 400/231

dengan pengukuran tahanan isolasi:

- Pimer-Sekunder $=25 \Omega$ (ohm .

- $\quad$ Primer-Ground $=15 \Omega \mathrm{ohm}$.

- $\quad$ Sekunder-Ground $=15 \Omega$ $\Omega$ mm

Dengan hasil tahanan yang sesuai dengan standart yaitu dengan $1 \Omega / \mathrm{Kv}$ dan tidak adanya kebocoran tahanan / kerusakan tahanan kecuali trafo nomer 7.

Pengukuran frekuwensi dan harmonisa tegangan dengan ETAP

Tabel.1Frekuensi dan harmonisa tegangan pada feeder (penyulang) LIS

\begin{tabular}{lllll}
\hline Order & $\mathrm{Hz}$ & $\mathrm{Mag}(\%)$ & $\mathrm{Mag}(\mathrm{A})$ & $\mathrm{Ang}\left({ }^{\circ}\right)$ \\
\hline 1 & 50 & 100 & 0 & 0 \\
\hline 11 & 550 & 9,1 & 0 & 0 \\
\hline 13 & 650 & 7,7 & 0 & 0 \\
\hline 23 & 1150 & 4,3 & 0 & 0 \\
\hline 25 & 1250 & 4 & 0 & 0 \\
\hline 35 & 1750 & 2,9 & 0 & 0 \\
\hline 37 & 1850 & 2,7 & 0 & 0 \\
\hline 47 & 2350 & 2,1 & 0 & 0 \\
\hline 49 & 2450 & 2 & 0 & 0
\end{tabular}

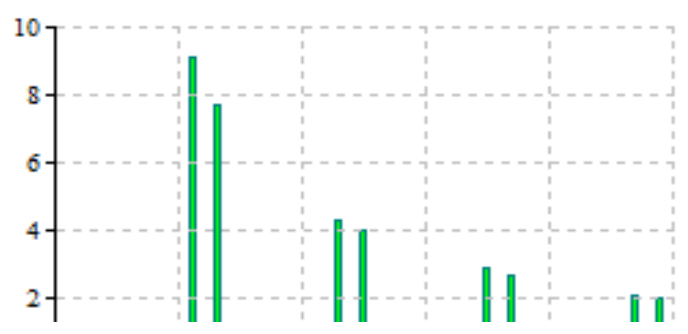

Gambar 1: Harmonisa tegangan pada penyulang LIS

(c) 2021 INFOTRON: Jurnal IImiah Teknik Informatika, Elektronika dan Kontrol (Scientific Journal of Informatics, Electronics and Control Engineering). 
Abidin.Z, dkk. et. al./INFOTRON 1 (1) 2021 hal. 11-23

Nilai distorsi tegangan harmonisa terbesar pada orde pertama $(50 \mathrm{~Hz})$ sebesar $100 \%$ dan pada orde ke$11(550 \mathrm{~Hz})$ sebesar 9,1\% di penyulang LIS.

Tabel 2 :Frekuensi dan harmonisa tegangan pada feeder (penyulang) Pambon

\begin{tabular}{|c|c|c|c|c|}
\hline Order & $\mathrm{Hz}$ & Mag (\%) & Mag (A) & $\begin{array}{l}\text { Ang } \\
\left({ }^{\circ}\right)\end{array}$ \\
\hline 1 & 50 & 100 & 0 & 0 \\
\hline 5 & 250 & 21,0 & 0 & 0 \\
\hline 7 & 350 & 13,05 & 0 & 0 \\
\hline 11 & 550 & 8,98 & 0 & 0 \\
\hline 13 & 650 & 7,1 & 0 & 0 \\
\hline 17 & 850 & 5,64 & 0 & 0 \\
\hline 19 & 950 & 4,81 & 0 & 0 \\
\hline 23 & 1150 & 4,06 & 0 & 0 \\
\hline 25 & 1250 & 3,58 & 0 & 0 \\
\hline 29 & 1450 & 3,11 & 0 & 0 \\
\hline 31 & 1550 & 2,81 & 0 & 0 \\
\hline 35 & 1750 & 2,48 & 0 & 0 \\
\hline 37 & 1850 & 2,27 & 0 & 0 \\
\hline 41 & 2460 & 2,03 & 0 & 0 \\
\hline 43 & 2580 & 1,87 & 0 & 0 \\
\hline 47 & 2820 & 1,68 & 0 & 0 \\
\hline 49 & 2940 & 1,55 & 0 & 0 \\
\hline
\end{tabular}

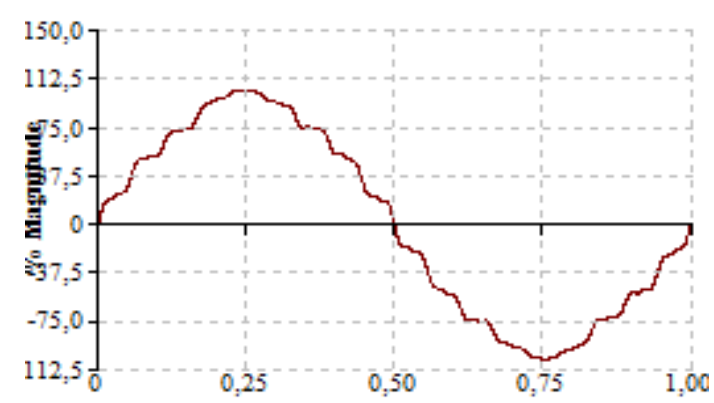

Gambar 2: Harmonisa tegangan pada penyulang pambon 
Nilai distorsi tegangan harmonisa terbesar pada orde pertama $(50 \mathrm{~Hz})$ sebesar $100 \%$ dan pada orde ke$5(250 \mathrm{~Hz})$ sebesar 21,0\% di penyulang Pambon.

Tabel 3 .Frekuensi dan harmonisa tegangan pada feeder (penyulang) Omya

\begin{tabular}{lllll}
\hline Order & $\mathrm{Hz}$ & $\begin{array}{l}\text { Mag } \\
(\%)\end{array}$ & Mag $(\mathrm{A})$ & Ang $\left(^{\circ}\right)$ \\
\hline 1 & 50 & 100 & 0 & 0 \\
\hline 11 & 550 & 8,3 & 0 & 0 \\
\hline 13 & 650 & 6,7 & 0 & 0 \\
\hline 23 & 1150 & 2,8 & 0 & 0 \\
\hline 25 & 1250 & 2,3 & 0 & 0 \\
\hline 35 & 1750 & 0,8 & 0 & 0 \\
\hline 37 & 1850 & 0,5 & 0 & 0 \\
\hline 47 & 2350 & 0,2 & 0 & 0 \\
\hline 49 & 2450 & 0,2 & 0 & 0 \\
\hline
\end{tabular}

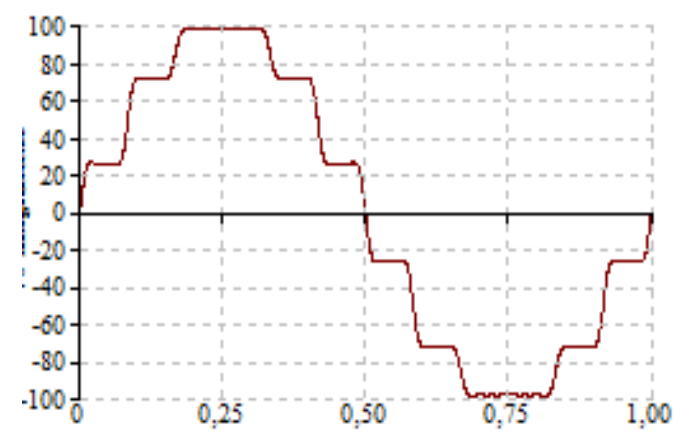

Gambar 3: Harmonisa tegangan pada penyulang omya

Nilai distorsi tegangan harmonisa terbesar pada orde pertama $(50 \mathrm{~Hz})$ sebesar $100 \%$ dan pada orde ke$11(550 \mathrm{~Hz})$ sebesar 8,3\% di penyulang Omya.

Tabel 4.Frekuensi dan harmonisa tegangan pada feeder (penyulang) Solokuro

\begin{tabular}{lllll}
\hline Order & $\mathrm{Hz}$ & $\begin{array}{l}\text { Mag } \\
(\%)\end{array}$ & Mag (A) & Ang $\left(^{\circ}\right)$ \\
\hline 1 & 50 & 100 & 0 & 0 \\
\hline 5 & 250 & 2,2 & 0 & 0 \\
\hline 7 & 350 & 1,1 & 0 & 0 \\
\hline
\end{tabular}


Abidin.Z, dkk. et. al./INFOTRON 1 (1) 2021 hal. 11-23

\begin{tabular}{lllll}
\hline 11 & 550 & 0,75 & 0 & 0 \\
\hline 13 & 650 & 0,57 & 0 & 0 \\
\hline 17 & 850 & 3,5 & 0 & 0 \\
\hline 19 & 950 & 2,7 & 0 & 0 \\
\hline 23 & 1150 & 0,2 & 0 & 0 \\
\hline 25 & 1250 & 0,16 & 0 & 0 \\
\hline 29 & 1450 & 0,14 & 0 & 0 \\
\hline 31 & 1550 & 0,12 & 0 & 0 \\
\hline 35 & 1750 & 1,1 & 0 & 0 \\
\hline 37 & 1850 & 1 & 0 & 0 \\
\hline 41 & 2460 & 0,09 & 0 & 0 \\
\hline 43 & 2580 & 0,08 & 0 & 0 \\
\hline 47 & 2820 & 0,08 & 0 & 0 \\
\hline 49 & 2940 & 0,07 & 0 & 0 \\
\hline
\end{tabular}

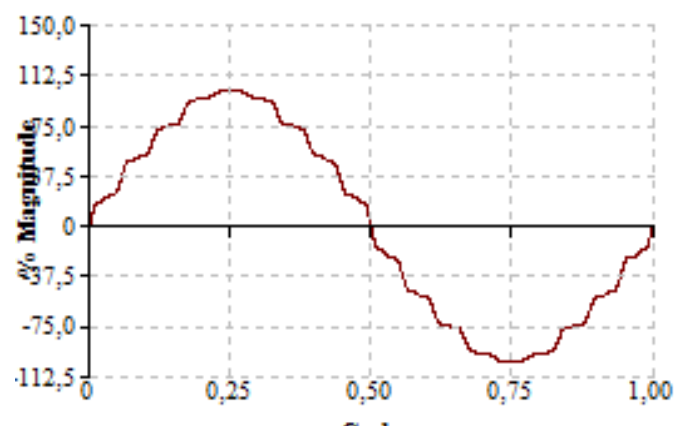

Gambar 4: Harmonisa tegangan pada penyulang Solokuro

Nilai distorsi tegangan harmonisa terbesar pada orde pertama $(50 \mathrm{~Hz})$ sebesar $100 \%$ dan pada orde ke$5(250 \mathrm{~Hz})$ sebesar 2,2\% di penyulang Solokuro.

Tabel 5.Frekuensi dan harmonisa tegangan pada feeder (penyulang) Pantura

\begin{tabular}{lllll}
\hline Order & $\mathrm{Hz}$ & $\begin{array}{l}\text { Mag } \\
(\%)\end{array}$ & Mag (A) & $\begin{array}{l}\text { Ang } \\
\left({ }^{\circ}\right)\end{array}$ \\
\hline 1 & 50 & 100 & 0 & 0 \\
\hline
\end{tabular}




\begin{tabular}{lllll}
\hline 5 & 250 & 20 & 0 & 0 \\
\hline 7 & 350 & 14,3 & 0 & 0 \\
\hline 11 & 550 & 9,1 & 0 & 0 \\
\hline 13 & 650 & 7,7 & 0 & 0 \\
\hline 17 & 850 & 5,9 & 0 & 0 \\
\hline 19 & 950 & 5,3 & 0 & 0 \\
\hline 23 & 1150 & 4,3 & 0 & 0 \\
\hline 25 & 1250 & 4 & 0 & 0 \\
\hline 29 & 1450 & 3,4 & 0 & 0 \\
\hline 31 & 1550 & 3,2 & 0 & 0 \\
\hline 35 & 1750 & 2,8 & 0 & 0 \\
\hline 37 & 1850 & 2,7 & 0 & 0 \\
\hline 41 & 2460 & 2,4 & 0 & 0 \\
\hline 43 & 2580 & 2,3 & 0 & 0 \\
\hline 47 & 2820 & 2,1 & 0 & 0 \\
\hline 49 & 2940 & 2 & 0 & 0 \\
\hline
\end{tabular}

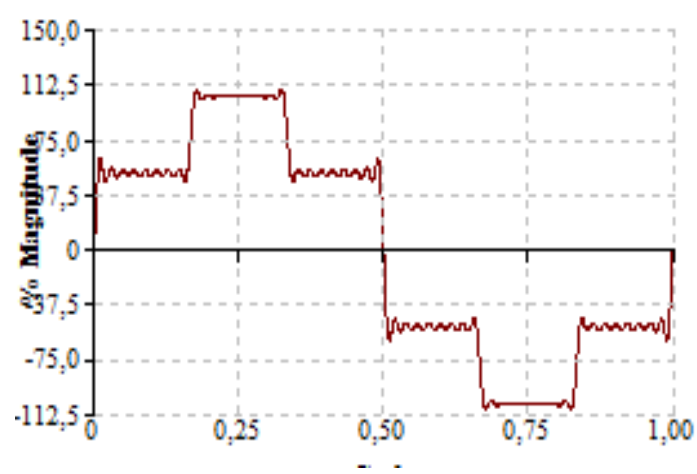

\section{Gambar 5: harmonisa tegangan pada penyulang pantura}

Nilai distorsi tegangan harmonisa terbesar pada orde pertama $(50 \mathrm{~Hz})$ sebesar 100\% dan pada orde ke$5(250 \mathrm{~Hz})$ sebesar $20 \%$ di penyulang Pantura.

\section{Pengukuran drop tegangan dengan aplikasi ETAP}

Di bawah berikut ini adalah contoh perhitungan setiap feeder dari data PT PLN (Persero) Rayon Brondong menggunakan program ETAP 12.0.

1. Feeder LIS 
Persentase 99,7\% hasil dari line70 adalah

$20 k V \times \frac{99,7}{100}=19,94 k V \Delta V=20 k V-19,94 k V \Delta V=0,06 k V$

Persentase drop

$\% \Delta V=\frac{\Delta V}{V} \times 100 \% \% \Delta \mathrm{V}=\frac{0,06}{20} \times 100 \%$

$\% \Delta V=0,3$

\section{Feeder OMYA}

Persentase 100,3\% hasil dari line108 adalah

$20 k V \times \frac{99,7}{100}=20,06 k V \Delta V=20 k V-20,06 k V \Delta V=-0,06 k V$

Persentase drop

$\% \Delta V=\frac{\Delta V}{V} \times 100 \% \% \Delta \mathrm{V}=\frac{-0,06}{20} \times 100 \% \% \Delta V=-0,3$

3. Feeder Pambon

Persentase 95,7\% hasil dari line1 adalah

$20 k V \times \frac{99,7}{100}=19,14 k V \Delta V=20 k V-19,14 k V \Delta V=0,86 k V$

Persentase drop

$\% \Delta V=\frac{\Delta V}{V} \times 100 \% \% \Delta \mathrm{V}=\frac{0,86}{20} \times 100 \%$

$\% \Delta V=4,3$

4. Feeder pantura

Persentase 96,1\% hasil dari line1 adalah

$20 k V \times \frac{96,1}{100}=19,22 k V \Delta V=20 k V-19,22 k V \Delta V=0,78 k V$

Persentase drop

$\% \Delta V=\frac{\Delta V}{V} \times 100 \% \% \Delta \mathrm{V}=\frac{0,78}{20} \times 100 \%$

$\% \Delta V=3,9$

\section{Feeder solokuro}

Persentase $98,8 \%$ hasil dari line2 adalah

$20 k V \times \frac{98,8}{100}=19,76 k V \Delta V=20 k V-19,76 k V \Delta V=0,24 k V$

Persentase drop

$\% \Delta V=\frac{\Delta V}{V} \times 100 \% \% \Delta \mathrm{V}=\frac{0,24}{20} \times 100 \%$

$\% \Delta V=1,2$

Tabel 6.hasil drop tegangan menggunakan program ETAP 12.0

\begin{tabular}{llll}
\hline & & Panjang & Rata-rata \\
No & Nama & JTM & $\Delta V(\%)$ \\
& Feeder & $(\mathrm{kms})$ & \\
\hline
\end{tabular}




\begin{tabular}{llll}
\hline 1 & Feeder LIS & 11,689 & 1,47 \\
\hline 2 & $\begin{array}{l}\text { Feeder } \\
\text { Omya }\end{array}$ & 29,562 & 3,61 \\
\hline 3 & $\begin{array}{l}\text { Feeder } \\
\text { Pambon }\end{array}$ & 74,535 & 7,86 \\
\hline 4 & $\begin{array}{l}\text { Feeder } \\
\text { Pantura }\end{array}$ & 25,839 & 4,98 \\
\hline 5 & $\begin{array}{l}\text { Feeder } \\
\text { Solokuro }\end{array}$ & 73,518 & 7,92 \\
\hline
\end{tabular}

Dari tabel 6 hasil perhitungan drop tegangan dengan program ETAP 12.0 dapat dibuat grafik sebagai berikut:

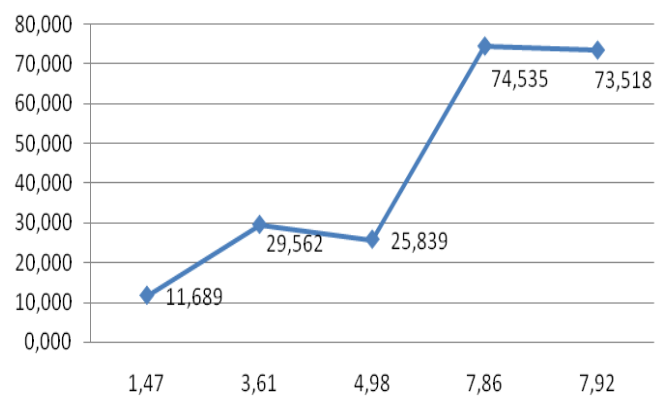

\section{Gambar 6. Grafik Drop Tegangan per feeder menggunakan program ETAP 12.0 (KMS/ $\Delta \mathrm{V}(\mathrm{kV}))$.}

Dari hasil perhitungan drop tegangan pada PLN Rayon Brondong masih memenuhi standart PLN 1 : 1978 kecuali feeder pambon. Penyebab utama terjadinya drop tegangan pada jaringan atau saluran distribusi antara lain karena panjangnya pendistribusian, beban per section dan luas penghantar jaringan menengah (TM). Titik drop tegangan yang buruk adalah titik paling jauh yaitu dari feeder Pambon dengan nilai menggunakan rumus sebesar 11,565\% dan program ETAP 12.0 sebesar 7,86\% karena panjang jaringan yang berlebihan dan hantaran kabel yang kurang besar sesuai dengan tabel 4.8. Panjang jaringan yang berlebihan pada feeder Pambon sepanjng 74,535 kilo meter sirkuit dan feeder Solokuro.

\section{Penanganan gangguan Transformator}

Menghilangkan gangguan sama sekali dalam suatu sistem tenaga listrik merupakan usaha yang tidak mungkin dapat dilakukan. Oleh karena itu maka usaha yang dapat dilakukan adalah mengurangi akibat kerusakan yang ditimbulkannya. Usaha-usaha yang dapat dilakukan adalah :

1. Mengurangi besarnya arus gangguan.

Untuk mengurangi arus gangguan dapat dilakukan dengan cara : menghindari konsentrasi pembangkitan (mengurangi short circuit level) menggunakan reaktor dan menggunakan tahanan untuk pentanahan netralnya.

2. Penggunaan lighting arrester dan penentuan tingkat dasar isolasi (BIL) dengan koordinasi isolasi yang tepat. 
3. Melepaskan bagian sistem yang terganggu dengan menggunakan circuit breaker dan relay pengaman.

4. Mengurangi akibat pelepasan bagian sistem yang terganggu dengan cara :

a. Penggunaan jenis relay yang tepat dan penyetelan relay yang selektif agar bagian yang terlepas sekecil mungkin.

b. Penggunaan saluran double.

c. Penggunaan automatic reclosing.

d. Penggunaan sectionalizer pada JTM.

e. Penggunaan spindle pada JTM atau setidak-tidaknya ada titik pertemuan antar saluran sehingga ketika ada kerusakan atau pemeliharaan tersedia alternative supply untuk maneuver.

f. Penggunaan peralatan cadangan.

5. Penggunaan pola load shedding dan sistem splitting untuk mengurangi akibat kehilangan pembangkit.

6. Penggunaan relay dan circuit breaker yang cepat dan AVR dengan response yang cepat pula untuk menghindari atau mengurangi kemungkinan gangguan instability (lepas sinkron).

\section{Penanganan Kerusakan}

Untuk penanganan gangguan trafo distribusi di PT. PLN rayon Brondong trafo yang rusak langsung diganti dengan trafo baru atau diganti dengan trafo semi permanen dari PT. PLN (persero) Area Bojonegoro karena tidak adanya teknisi khusus untuk menangani kerusakan trafo distribusi.

\section{Kesimpulan}

1. Dari hasil analisa dalam perawatan trafo distribusi $20 \mathrm{Kv}$ di PT. PLN (persero) Rayon Brondong dengan pengukuran yang telah dianalisa tahanan isolasi dengan Mega Ohm Meter (megger tester) 500/1000 V hanya ada satu trafo yang kumparanya bocor yaitu pada trafo nomor 7 yang ada di tabel dalam 10 sample yang diambil. Dan mengukur keandalan daya dengan menentukan frekwensi sistem dengan menggunakan program ETAP 12.6.0, dalam data (F= $50 \mathrm{~Hz}$ ), data kesetabilan tegangan hanya pada feeder Pambon dan Solokuro yang nilai Harmonisnya paling rendah, dari hasil perhitungan drop tegangan pada PLN Rayon Brondong masih memenuhi standart PLN kecuali feeder pambon.

2. Pada penanganan gangguan dan kerusakan $20 \mathrm{Kv}$ di PT. PLN (persero) Rayon Brondong telah memenuhi kualitas daya (power quality) karena pada penanganan gangguan telah memenuhi Standar Operasional Prosedur PLN. Dan saat kerusakan pada trafo, PT. PLN (persero) Rayon Brondong langsung mengganti dengan trafo yang baru ataun diganti dengan trafo mobil (semi permanen) yang di datangkan langsung dari PT. PLN (Persero) distribusi jawa timur area Bojonegoro.

\section{Refrensi}

Ade Setiawan. 13 January 2011. distribusi frekwensi. Dunialistrik.blogspot.com.

Bachtiar yusuf effendi. Juni 2017. Analisis drop tegangan pada PT. PLN (persero) unit Brondong. Tugas akhir fakultas Teknik Elektro Universitas Islam Lamongan.

Roy Hakim Peranginangin. 2009 studi analisis pengaruh harmonisa terhadaptransformator distribusi. Universitas Sumatra Utara.

Daman Suswanto. Analisis gangguan pada jaringan distribusi. Jurnal Sistem Distribusi Tenaga Listrik. 
H. Sugiarto 2013. Kajian Harmonisa Arus Dan Tegangan Listrik di Gedung. Jurnal Penelitian.

Hadi, abdul. 1991. Sistem Distribusi Daya Listrik. Jakarta : Erlangga

Hanif Guntoro. 3 september 2010. Kualitas daya listrik (Power Quality). http://aimarbanget.blogspot.co.id/3/9/2010/power-quality.html.

Hanif Guntoro. 14 Januari 2009. Perawatan Dan Pemantauan Kondisi Transformator. Artikel blog dunia listrik.

Hanif guntoro. 18 september 2008. Keandalan dan kualitas listrik. Artikel blog dunia listrik.

Heryadik Simatupang. 2014. Pemeliharaan Transformator. Makalah Transformator. Jurusan Pendidikan Teknik Elektro Fakultas Teknik Universitas Negri Medan.

M. Hariansyah, Ir., M.T. 2010. Teknik Pemeliharaan Transformator Distribusi Pada Gardu Tiang Portal. jurnal. Dosen Tetap Fakultas Teknik UIKA Bogor.

Margiono Abdillah. 2010. fungsi mega ohm meter (megger). https://deltaenggineer.wordpress.com.

Rifqi Muhammad. 2010. Operasi dan Pemeliharaan Jaringan Distribusi Tegangan Menengah 20 kV, Semarang.

Riqi Riyadi. 04 Desember 2013. Analisa Gangguan Gardu Trafo Tiang Pada PT. PLN (Persero) Area Ternate. Jurnal penelitian.

Yovi Muhammad casimy. Analisis kerusakan dan pemeliharaan Transformator di gardu induk pauh limo Padang. PLN (persero) Padang.

yusuf taufani. 2010. Cara Menggunakan Megger Untuk Mengukur Tahanan Isolasi Listrik. https://Detilkan.blogspot.com. 